\title{
A LONGITUDINAL SURVEY OF THE OCCURRENCE OF SALMONELLA IN PIGS AND THE ENVIRONMENT OF NUCLEUS BREEDER AND MULTIPLIER PIG HERDS IN ENGLAND
}

A. D. Wales' ${ }^{1}$ I. M. McLaren', S. Bedford ${ }^{1}$, J. J. Carrique-Mas' ${ }^{1}$ A. J. C. Cook ${ }^{2}$, R. H. Davies $^{1}$

${ }^{1}$ Department of Food and Environmental Safety, Veterinary Laboratories Agency, Woodham Lane, New Haw, Addlestone, Surrey KT15 3NB, United Kingdom

${ }^{2}$ Centre for Risk Analysis \& Epidemiology, Veterinary Laboratories Agency, Woodham Lane, New Haw, Addlestone, Surrey KT15 3NB, United Kingdom 


\section{Summary}

Epidemiological findings are reported from pig breeding units that were visited repeatedly and sampled intensively for environmental Salmonella contamination. Eight pig breeding units previously associated with Salmonella Typhimurium were visited during up to seven years. Samples from voided faeces, surfaces, fomites and wildlife were cultured. Certain serovars were isolated repeatedly on certain units, whilst others were detected only once or intermittently. A few serovars were isolated consistently on some units but only intermittently on others. There was an association between Salmonella in pens and in their immediate environment. S. Typhimurium was significantly associated with growing pigs. Pens holding breeding stock for production herds were frequently Salmonella-positive. Herds under common ownership showed similar serovar combinations. Cleaning and disinfection was frequently ineffective. Wildlife serovars were typical of the associated premises. On one unit, a low level of Salmonella was attributed to a small herd size, good cleaning and disinfection and good rodent control. The study has shown that breeding herds are susceptible to endemic infections with multiple Salmonella serovars and that cleaning, disinfection and vector control may in many cases be inadequate. Finally, the prevalence of $S$. Typhimurium may be greater in youngstock, which has important implications for public health. 


\section{Introduction}

Human non-typhoidal salmonellosis remains a significant issue in public health. There were 14060 reported cases in the UK in 2006 (Anon 2007b) and three or more times that number of cases are estimated to go unreported (Wheeler and others 1999). Salmonella Typhimurium is consistently the second commonest serovar isolated from people in the European Union (EU), and is associated with consumption of contaminated pig, poultry and bovine meat (Anon 2007a, b). Recent assessments of the contribution of pork and pork products to human non-typhoidal salmonellosis have yielded figures of around 22\% of cases in the Netherlands and 14\% of cases in Denmark (Anon 2006).

Colonisation of pigs with those Salmonella serovars currently encountered in the EU is typically asymptomatic and involves limited invasion of tissues, including mesenteric lymph nodes (Reed and others 1985, 1986, Wood and others 1989). Excretion can persist for several months following experimental exposure of young animals (Wood and others 1989), but the prevalence of individuals in which excretion can be detected falls sharply over the first few weeks post-exposure and then usually becomes intermittent (Nielsen and others 1995, Berends and others 1996, Cook 2004). A few Salmonella serovars usually predominate within a national pig population, with some regional variation. Recently, a comprehensive survey of ileo-caecal lymph nodes from nearly 20000 pigs was undertaken in EU member states (Anon 2008a). The weighted EU-level Salmonella prevalence was $10.3 \%$ of pigs, and the prevalence observed in 639 samples from the UK was $21.2 \%$. Serovars Typhimurium and Derby were heavily predominant, with community-wide individual animal prevalences of $4.7 \%$ and $2.1 \%$, respectively. Forty percent of Salmonella-positive pigs were infected by $S$. Typhimurium and this serovar was most frequent in the UK and in the EU as a whole. These results are consistent with findings from previous investigations in the EU and Canada (Baggesen and others 1996, Berends and others 1996, Letellier and others 1999, Davies and others 2004, Nollet and others 2004, Anon 2005, 2008b).

Nucleus herds maintain and improve pure male- and female-trait breeds at the apex of the pyramid, whilst multiplier herds cross nucleus breeds to produce commercial breeding animals. If these herds (collectively referred to hereafter as genetic breeder herds) are infected with Salmonella, they have a clear potential to disseminate it to herds producing pigs for slaughter, but there are limited data on the prevalence and epidemiology of Salmonella colonisation in pig herds above the commercial production tier of the breeding pyramid. Sampling of ten pooled pen faeces samples from young pigs yielded Salmonella from $11.7 \%$ of Danish genetic breeder herds, whereas the same sampling regime yielded Salmonella from $17 \%$ of sow herds breeding pigs for slaughter (Christensen and others 2002). S. Typhimurium predominated, and individual animal prevalences within herds were typically low. Serological examination, with a mix ELISA, of 46 Dutch multiplier herds revealed at least one seropositive pig in between $91 \%$ and $100 \%$ of herds, depending on the optical density (OD) cut-off used (van der Wolf and others 2001). One of four Greek multiplier herds proved seropositive by ELISA similar to that used in Danish monitoring (Grafanakis and others 2001).

These limited survey reports suggest that the herd and individual prevalence for Salmonella excretion or exposure is broadly similar between genetic breeder and production breeding herds. The present study aimed to examine patterns of Salmonella excretion and contamination in nucleus and multiplier herds in England. The data collected allowed comparisons between categories of stock and also a longitudinal analysis from a series of visits spanning months to years. The study included all Salmonella serovars, but focused on $S$. Typhimurium and used bacteriological culture of pooled faeces collected from pens and of environmental samples as an approach which provided typable isolates from specific locations on farms without excessive disruption or animal stress. 


\section{Materials and Methods}

\section{Pig units}

Nucleus or multiplier farms that had submitted a diagnostic sample from which $S$. Typhimurium was isolated or another farm under the same ownership were invited to receive free follow-up intensive sampling visits. The results from each visit were provided to owners and their private veterinary surgeons to inform control actions. Farms A and B were both 700 sow nucleus breeding units producing gilts and boars and under common ownership. Farms $\mathrm{C}$ and $\mathrm{D}$ were nucleus gilt-producing units of 550 and 150 sow size respectively, also under common ownership. Farm E was, at the first visit, a 400 sow unit producing pigs for slaughter and at the second visit a unit undergoing depopulation, cleaning and disinfection (C\&D) before becoming a nucleus breeding unit. Farms X, Y and $\mathrm{Z}$ were, respectively, 800, 200 and 1100 sow multiplier units. Each of these three farms was managed by a separate large integrated company, and each supplied maiden gilts for service on commercial breeding farms throughout the corresponding organisation.

All were indoor units, although Farm $\mathrm{Z}$ had some outdoor weaner kennels. Buildings for breeding pigs were yards or pens of concrete and/or metal construction, with concrete flooring overlaid by deep-litter straw bedding (yards) or thinner layers of straw (pens). Standard farrowing crates were used, most of which were on raised concrete or metal flooring with a perforated or slatted dunging area. Newly-weaned pigs were housed in raised perforated metal or plastic floored pens or wooden kennels with a thin layer of straw and a perforated dunging area. Older pigs being reared for onward sale were housed on concrete floors that included lightly straw-bedded a kennel areas with a thin layer of straw and push-through dunging areas. All feed used on the farms was commercial compound pelleted feed supplied by national compounder feed mills.

\section{Sampling}

All groups of pigs from all age groups present were sampled, plus empty and cleaned accommodation, equipment, walls and floors in pig-handling and staff areas, also wildlife with a particular emphasis on rodents. Sampling was performed in the context of individual investigations of issues on each unit, and therefore the focus and intensity of sampling varied between premises and visits.

Pen or yard samples consisted of $25 \mathrm{~g}$ of naturally pooled faeces, each pool thereby representing a discrete group (of variable size) occupying a bounded space. The faeces were gathered using a swab of sterile medical gauze soaked in buffered peptone water (BPW) that was passed in an ' $\mathrm{S}$ '-shaped sweep through the dunging area of each pen, covering approximately $0.5 \mathrm{~m}^{2}$. Categories of animals thus sampled were: pregnant sows, mature boars/service pens, young boars/gilts, finishers, and weaners/growers. In farrowing houses, samples consisted of a swab from all available faeces present in an individual farrowing crate (including piglet faeces if present), or from surfaces if faeces was not present following C\&D. For each category present on a premises, the number of groups, pens or farrowing crates sampled varied from visit to visit, according to stocking levels and arrangements. The intention was to visit and sample premises every six months, although the actual frequency achieved was somewhat less, governed by the access granted by unit owners and the availability of sampling staff. Samples taken from the 'environs' of pens, including cleaned and disinfected pens, generally comprised $0.5 \mathrm{~m}^{2}$ surface swabs of the walls and floors of passageways in the same accommodation space. Samples following C\&D were taken according to what was available at each visit, so the group categories sampled in this manner varied from visit to visit. Equipment (including slurry scrapers, feed barrows, handling equipment, pressure washers, tractors, loaders and trailers) was also surface-swabbed, and samples were taken of dust within bulk feed hoppers. Samples from wildlife consisted predominantly of faeces, identified according to animal group (rodent, bird, dog, cat, fox), plus dead mice. 


\section{Microbiological examination}

Faeces and environmental swabs were placed directly into $225 \mathrm{ml}$ BPW. Rodent and other wildlife droppings (1-10 g) and the liver, intestine and spleen from aseptically dissected mouse carcases (2$3 \mathrm{~g}$ ) were placed in an approximately tenfold volume of BPW at the processing laboratory. Samples were taken to the laboratory under ambient temperature conditions and processed on the day of collection.

Samples in BPW were pre-enriched at $37{ }^{\circ} \mathrm{C}$ for $18 \mathrm{~h}$, and then $0.1 \mathrm{ml}$ of the pre-enriched mixture was inoculated onto modified semi-solid Rappaport-Vassiliadis agar containing $0.01 \%$ novobiocin (MSRV; Difco 218681) and incubated at $41.5^{\circ} \mathrm{C}$ for $24 \mathrm{~h}$. A $1 \mu \mathrm{lloop}$ from the edge of any opaque growth on MSRV was inoculated onto Rambach agar (Merck 107500). Rambach and associated MSRV plates were incubated at $37^{\circ} \mathrm{C}$ and $41.5^{\circ} \mathrm{C}$ respectively for $24 \mathrm{~h}$. Any MSRV plates on which the growth had spread widely, but which were negative for Salmonella on the Rambach plates, were subcultured again onto Rambach agar after 48 hour's incubation on MSRV. Serotyping of one representative Salmonella colony per positive sample, plus phage-typing of Typhimurium isolates, was performed at the Salmonella reference laboratory at VLA - Weybridge.

\section{Data and statistical analysis}

The proportion of positive samples was calculated for different production group categories (boars/service areas, sows, farrowing accommodation, weaner pens/decks, grower/finisher pens, gilt pens), and also for rodent samples and for areas following C\&D. Within production group categories the sampling unit was the pen, or farrowing pen, as each faeces pool or swab comprised a unique sample for a pen on that occasion. In addition, for each visit there was an overall proportion of positive samples that additionally included results from samples of pen environs, equipment, other wildlife and the wider farm environment.

Several analyses were performed:

- For each stock category, the probability of a faecal sample yielding Salmonella was examined, using a two-level logistic regression mixed hierarchical model (Goldstein 2003).and the outcome was the logit of the probability of a sample testing positive for Salmonella. Three models were fitted: one for any Salmonella isolation, one for $S$. Typhimurium isolation, and one for non-Typhimurium Salmonella isolation.

- Evidence for a correlation between the presence of a Salmonella serovar in pens and in their environs (as defined above) was examined, using paired data from all occasions where groups of pens plus their environs had been sampled at the same time. Following identification of these cases, paired outcomes were derived: if the serovar was isolated from any pen in the group, or from any associated environs sample, then the outcome 'pens positive', or 'environs positive', was recorded. For each serovar, relative risks (or risk ratios) and exact $95 \%$ confidence intervals were calculated in order to compare the probabilities of a group of pens testing positive or negative given that the environs were positive or negative (Thrusfield 1995). As the numbers of qualifying data pairs for each serovar were small, the associations were tested using standard Fisher's exact test p- values. The analysis was performed for each serovar separately, with data from each farm visit being included only if that serovar had been isolated anywhere on the farm on that visit. Serovars for which the data was too sparse or skewed to yield meaningful results were not subjected to statistical analysis.

- Sample results from mobile equipment (including tractors, trailers, small loaders, washers, brushes and shovels) were examined, to consider the potential role of such equipment in disseminating Salmonella. 
- The efficacy of C\&D was examined by comparing the proportions of Salmonella-positive samples obtained from cleaned and from uncleaned areas.

- A descriptive analysis of longitudinal (temporal) patterns of pen-level prevalence and serovar dominance was performed for each premises.

The two-level hierarchical model (samples nested within farms) was fitted using MLWin 2.01 (Institute of Education, London). Statistical calculations were performed using Statcalc in the EpiInfo (US Centers for Disease Control) computer package.

\section{Results}

Farms A and B were each visited on three occasions over two years, Farm C on two occasions one year apart, Farm D on one occasion and Farm E on two occasions nine months apart. Within each production category, the number of samples collected on a visit varied within a range of zero (for 27 of the potential 144 visit/category combinations) to 151 , with a median of 30 . When no samples were collected from a category, this was because that category of animal was not present on the farm at that visit. Figure 1 shows the overall proportion of Salmonella-positive samples for each visit to farms A, B, C and E together with the Salmonella serovars and $S$. Typhimurium definitive phagetypes isolated. Figure 2 illustrates the subset of data derived from sample categories (pens, C\&D, rodents), showing the median and the range of single-visit proportion positive values, broken down by the sample categories.

Farm X was sampled comprehensively on seven occasions over six and a half years, with additional limited sampling of cleaned and disinfected areas between the first and second main visits. Farm Y was visited on five occasions over three years, and a single visit was made to Farm Z. Figure 3 summarises the proportion positive and Salmonella types (serovars and S. Typhimurium phagetypes) found over time on farms $\mathrm{X}$ and $\mathrm{Y}$. A diverse collection of strains were isolated from samples collected in the single visit to Farm $Z$. The likely presence of several serovars in a single sample will have reduced the sensitivity of culture unpredictably, since the range of serovars present, total number of each serovar and their ability to compete and grow in laboratory conditions are all uncertain. Therefore, we considered it was more appropriate to describe areas from which multiple samples were collected as positive or negative for STM rather than report individual results. Figure 4 shows the proportion of samples that were positive for all serovars by sample category on Farm Z.

\section{Stock category associations with Salmonella}

Table 1 shows the proportions of Salmonella-positive samples, organised by category, by farm and by farm type. Table 2 shows the outputs of the three random effects hierarchical models. Farm $\mathrm{Z}$ was excluded from this analysis because, as discussed above, the presence of multiple serovars probably reduced the likelihood of isolating $S$. Typhimurium from individual samples. The reference is the farrowing areas, which had the lowest proportion of positive samples, with the model giving the odds of a positive sample in relation to these. The 'Finishers' category was excluded, since the sparsity of data from this category caused the model to become unstable when it was included. Compared with farrowing sows, there was a significantly higher risk of $S$. Typhimurium isolation from young stock (weaners plus growers, gilts plus young boars; odds ratios $=6.82$ and 7.39 , respectively) and also from non-lactating mature stock (dry sows plus mature stock boars), although the risk was less elevated for these groups (odds ratios $=2.46$ and 2.59, respectively). The pens of weaners and growers were significantly more likely to yield $S$. Typhimurium than were any of the mature animal pens.

For young boars and gilts, i.e. the stock closest to the point of dispatch to production herds as breeding animals, the pen-level prevalence for all Salmonella serovars ranged from zero to $100 \%$, with a median value of $43 \%$. 


\section{Examination of adjacent environment contamination}

The association between the presence of each identified Salmonella serovar within a pen and within samples from the adjacent environment was estimated and results are shown in Table 3. These demonstrate that the presence of $S$. Typhimurium or $S$. Panama in a pen was strongly associated with the same serovar being detected from the immediate environment. The results also suggest that the presence of $S$. Derby in a pen is likely to be associated with its presence in the immediate vicinity, although this result did not attain conventional statistical significance.

\section{Efficacy of cleaning and disinfection}

Table 4 summarises the results from visits where cleaned and disinfected accommodation had been sampled, comparing these samples with samples from similar uncleaned areas at the same visits. It can be seen that C\&D was commonly, but not invariably, associated with a lower proportion of positive samples in farrowing accommodation, and that Salmonella was detected post-C\&D on about half of the sampling occasions. For other areas (considered together because of limited data), the proportion of Salmonella-positive samples was similar in both cleaned and uncleaned areas.

\section{Mobile and feed equipment}

As there were relatively few samples taken from mobile equipment, data from all farms were combined, giving an overall proportion of Salmonella-positive samples of 66/128 (52\%). Salmonella was not found in feed hopper dust or in feed barrows.

\section{Potential wildlife vectors}

Findings from all farm visits that included samples from wildlife, including rodents, are presented in Table 5. There was no Salmonella serovar or phage-type found in wildlife samples that was not also found in other samples from the same farm on the same visit. The overall proportion of Salmonellapositive samples from wildlife was similar between rodents, birds and others, and was in addition similar to that from all other samples.

\section{Longitudinal analysis at farm level}

Nucleus breeder farms: At Farm A, Salmonella was isolated from all sampled categories on all occasions. The proportion of Salmonella-positive samples was highest (62\%) at the first visit and lowest (39\%) at the final visit. S. Typhimurium DT104 was initially found at high frequency (33\%) among young boars and gilts being reared for sale, and also among weaners and rodents. This frequency was zero at the final visit.

A high frequency of Salmonella isolation was also encountered on Farm B. Dry sows showed a consistently high proportion of $\geq 85 \%$, farrowing sows were lower at between 33 and $45 \%$, and positive proportions for younger stock were more variable, at between 17 and $61 \%$. S. Typhimurium DT104 was detected only among young boars, gilts and weaners initially, but was found in dry sows, boars and rodents by the final visit. Improved rodent control but poor C\&D efficacy during the study had little observable impact on the frequency of Salmonella isolation.

On Farm C, Salmonella was isolated frequently on both visits, with 10 to $100 \%$ of samples positive in individual categories of pig $S$. Typhimurium was initially isolated amongst weaners, finishers and samples from rodents in the same areas, but one year later it was detected much more widely. Within affected categories, $10 \%$ to $41 \%$ of samples were positive for this serovar. Phagetype DT104 predominated. S. Give was frequently isolated on both visits and across all categories, whilst other serovars were occasionally isolated. Rodent control was notably poor. 
On Farm D, Salmonella was isolated from a modest $14 \%$ of samples, with the highest frequency of isolation in the sow yards, where rodent control was inadequate. $S$. Give was the predominant serovar, similar to Farm C from where some stock had been received, but $S$. Typhimurium was not found. The stock had been moved from Farm C to Farm D before $S$. Typhimurium was found to be common in most stock groups on Farm C.

On Farm E, Salmonella was isolated frequently on both visits, with no category of stock having less than $30 \%$ positive samples. Initially, $S$. Typhimurium (untyped) was isolated infrequently, with only grower pens, rodents and other wildlife yielding the serovar. Eight months later, this serovar was isolated more frequently (15 to $62 \%$ of samples) across all categories except dry sows. $S$. Stanley was widespread, but other serovars were restricted to older stock..C\&D using a peroxygen disinfectant was ineffective (Table 4) but repeat disinfection of the whole site using 5\% formalin after total depopulation (data not shown) resulted in no isolates from 240 samples.

Multiplier farms: On Farm X, routine tetracycline medication of breeding sows ceased between the first and second visits. The frequency of Salmonella isolation ranged between 16 and $57 \%$ of samples per visit. Within stock categories values ranged between $3 \%$ and $88 \%$, with a median figure of $27 \%$. The frequency of isolation of non-Typhimurium salmonellas differed markedly and without regular patterns from visit to visit; amongst the stock categories, most variation was seen in weaner pens. $S$. Manhattan was persistent in most sample categories throughout the seven years and $S$. Derby was widespread on the first and the last four visits, but was not detected in the intervening period. $S$. Typhimurium initially was frequently isolated but latterly it was found only amongst young stock, and finally at only $1 \%$ of samples from these groups. Hospital pens were heavily contaminated, first with $S$. Typhimurium and latterly with other serovars. Initially, rodent faeces were heavily contaminated with herd serovars, but opportunities to sample declined sharply as rodent control improved.

Farm Y showed a particularly varied pattern of Salmonella isolation frequency from visit to visit, with an alternating pattern of apparent dominance by serovars Panama and Typhimurium observed throughout the sampling period (Figure 3). Initially, S. Panama was prevalent in the farrowing accommodation $(25 \%)$ and found at lower frequencies elsewhere. On this first visit $S$. Typhimurium DT208 was found only in wild bird faeces, but nine months later it was frequently isolated among gilt pens and detected also in other groups. $S$. Typhimurium DT104L was also isolated from gilts in isolation pens after purchase from a primary breeding company. A year later $S$. Panama was again prevalent in all age groups of pigs, plus among rodents, and no Typhimurium was found. $S$. Derby was found for the first time amongst incoming and established gilts on this third visit. Five months later, serovars Panama, Derby and Typhimurium DT104B (which is closely related to DT104L) were isolated at modest frequency (3-10\% of samples) from weaner, dry sow and gilt pens, respectively. Higher frequencies of isolation were evident a year later, dominated by $S$. Typhimurium DT208, particularly amongst farrowing and young stock. S. Panama was found at low frequency among sows. C\&D proved to be inconsistently effective and contamination was found on cleaning equipment itself at one visit.

On Farm Z Salmonella was found to be widespread, with the exception of farrowing sows (Figure 4) $S$. Typhimurium was found amongst weaners, rodents and in service and hospital pens,. Phagetype U288 was predominant. The serovar most commonly isolated was Ohio, which was also very widespread extending to staff clothing and rooms, vehicles and a public road outside the farm.

Strain persistence: Certain serovars and phage-types were repeatedly isolated from certain premises: for nucleus herds these were Derby, Stanley, Give, Bredeney, Mbandaka and Typhimurium DT104; for multiplier Farm X these were Manhattan, Derby and Typhimurium, and for Farm Y they were Panama and Derby. Other types were isolated infrequently or intermittently: these were Senftenberg, Agona, Ajiobo, Rissen, Meleagridis and Typhimurium DTs 120, 104B, 20 and 193 in nucleus 
breeders, Bredeney, Newport, Muenchen, Heidelberg and Montevideo on multiplier Farm X, and Typhimurium on Farm Y.

Management changes during the study: The farm visits were made in the context of attempts at improved Salmonella control. Recommendations were made to unit managers after each visit, which is a potential source of bias in the data for the units sampled more than once. In addition, one unit (X) changed ownership and underwent a cycle of depopulation, cleaning and repopulation. Recommendations throughout centred upon improving rodent and wild bird control and better selection and application of disinfectants. These recommendations were generally made repeatedly, indicating that they were implemented poorly or not at all. On two farms (B and X), rodent control improved substantially. On some occasions advice was also given on avoiding continuous occupation, quarantine facilities, feed or water acidification and on emergency Salmonella vaccination, although none of these were noted to have been implemented on follow-up visits.

\section{Discussion}

Using targeted bacteriological sampling of the environment of pig breeding herd premises, the present study found associations between $S$. Typhimurium and immature stock, and between contamination of pens and of their adjacent environment by Salmonella. In addition, cleaning and disinfection was shown to be frequently ineffective for the reduction of Salmonella contamination, and mobile farm equipment was often Salmonella-positive. Isolates from wildlife reflected those from the farm in each case.

For the present nucleus and multiplier units the proportions of Salmonella-positive pens were comparable to pen-level Salmonella prevalences in UK finisher units (around 22\%) reported by Cook (2004), and to individual pig prevalences of 21 to $23 \%$, found within production herds at slaughter in the UK (Davies and others 2004, Anon 2008a). An EU-wide slaughter survey (Anon 2008a), yielded an overall individual Salmonella prevalence of $10.3 \%$.. It should be borne in mind that the present herds were studied because of a prior association with $S$. Typhimurium, that sampling was not randomised, and that the sensitivity of detection varies with methodology and sample type between studies. Pooled faeces used in the present study should provide a sensitive measure of pen contamination (Arnold and others 2005), but the stress of transport and lairage will affect findings from slaughterhouse surveys (Berends and others 1996, Davies and others 2000, Larsen and others 2003). Therefore, the present results cannot be used in direct comparison with most other data, but they do suggest that there is a Salmonella problem in some primary breeding herds that appears to be of a similar magnitude to that in many production herds.

Amongst nucleus breeder herds, the present findings showed several Salmonella serovars, including Typhimurium, to be widespread on four establishments (A to D), and on another farm (E) shortly before conversion to a primary breeder. Similarly, Salmonella was isolated frequently from the multiplier herds. There were no consistent differences between patterns of Salmonella isolation, or the overall risk of detecting Salmonella, for nucleus versus multiplier breeders, but neither were similar patterns seen on all farms.

Some observations can be made about the patterns observed with specific serovars. Combined data from all visits shows that $S$. Typhimurium was significantly more prevalent in samples from immature stock than from older stock, a pattern that was not seen among the other serovars when considered as a group, and which is consistent with an association between $S$. Typhimurium and post-weaned pigs reported elsewhere (Davies and Wray 1997). The probabilities modelled refer to average 'per farm' estimates. No adjustment within the farm estimates for the number of samples taken per visit was possible using hierarchical modelling, owing to the sparsity of some data subsets making the models unstable. For farms sampled more than once there were generally wide variations 
in the proportions of positive samples from visit to visit (figures 1,2 and 3), and this variability could not be incorporated into the models. For these reasons, caution should be exercised in the interpretation of results.

Nonetheless, the association observed between $S$. Typhimurium and immature stock is consistent with the temporal patterns seen in the longitudinal analysis. On premises where $S$. Typhimurium was seen to increase over time (farms B, C and E), it apparently extended from weaners and growers, and in some cases young gilts and boars, into older groups. Where $S$. Typhimurium, of varying phagetypes, decreased over time (Farms A and X), initial colonisation was in one case (A) restricted to these same young age groups and spread no further, but in the other (X) it was initially widespread but ultimately restricted to less than $2 \%$ prevalence among growers only. Therefore, weaner and grower stock were the groups most likely to show the presence of serovar Typhimurium on farms in the present study, and it tended to persist in these groups regardless of whether it was increasing or decreasing in prevalence elsewhere.

Excluding transient strains, temporal patterns of non-Typhimurium serovar prevalence varied widely. On Farm X, the prevalences varied widely between visits and a reduction in Salmonella after the withdrawal of tetracycline medication proved to be short-lived. On this farm, hospital pens consistently showed heavy contamination, and they might therefore prove to be a sensitive site for Salmonella detection on occasions when sampling opportunities are limited. Some of the infrequent or transient serovars (i.e. Mbandaka, Rissen) are feed-related types, possibly introduced in the pelleted diets used on all units. Systematic sampling of feed and feed equipment was not undertaken in the present study. Others are likely to be minority serovars which were circulating on the farms but perhaps were relatively poorly-adapted to persist in the conditions found on certain premises. Some (Kedougou and Newport) appeared to persist on some nucleus breeder premises and not on others.

Salmonella organisms may persist outside of the animal for days to months, depending on the microenvironment (Boes and others 2005, You and others 2006), and therefore their transmission and maintenance between animals or groups of animals may be promoted by adaptations not only to the host but to the farm environment (Berends and others 1996, Davies and Wray 1996). Studies have indicated that differing patterns of strains are found amongst breeding versus growing stock within the same operation (Davies and others 1998, Funk and others 2001), an example in the present data being the particular persistence of $S$. Typhimurium in young stock. This may reflect strain adaptation to local host and environment (Berends and others 1996). However, immunological mechanisms may also play a role in the separation of strains between different stages of production, as there may be limited correlation even between strains found in nursing sows and their piglets (Funk and others 2001), and maternal seropositivity to $S$. Typhimurium proved protective for excretion of this serovar among pre-weaned piglets (Kranker and others 2003). The prevalence of Salmonella excretion and the degree of serological response in growers tends to increase after around 10 weeks of age (Berends and others 1996, Nollet and others 2005b, Roesler and others 2005, 2006), and it may be that passive maternal immunity is partially protective for weaned piglets until this time.

In some units with excellent hygiene and a single established Salmonella serovar, weaning to clean accommodation can effectively eliminate infection from young growing stock (Dahl and others 1997, Nietfeld and others 1998), but in many operations there is more than one endemic strain and in addition depopulation plus C\&D of onward accommodation to a sufficient standard is not regularly achieved. Furthermore, a proportion of salmonellas acquired around birth and nursing do appear to persist in older pigs (Berends and others 1996), and clonal strains of Typhimurium DT108, Anatum and Derby have been found at all levels of an integrated multi-site production unit (Letellier and others 1999). Thus, strains endemic in post-weaning units are likely to be transmitted infrequently from the breeding herd, or to have originated from a prior infection in the breeding herd before development of 'herd immunity'. 
In the present studies, the smaller farms (D and Y) had fewest concurrent serovars detected, despite the number of samples taken per visit (around 220) being similar to the study average of 294. Farm D had a low overall prevalence of Salmonella, despite receiving stock from a farm (C) with a comparatively high prevalence and number of strains. This suggests that recycling of environmental contamination is likely to play a significant part in the occurrence and prevalence of Salmonella on pig farms. Farm Y showed an interesting and dynamic pattern in its small herd, alternating between periods of dominance by $S$. Panama (which also occurred throughout the integration served by this multiplier herd) and S. Typhimurium DT208, which occurred in many of the commercial herds within the company. S. Typhimurium DT208 was initially found only in wild bird faeces, but nine months later it was the dominant strain in the herd. This is consistent with a role for wild birds as sentinel or possible vector species for Salmonella in pigs. S. Derby and S. Typhimurium DTs 104L and 104B appeared all to be introduced to Farm Y by gilts, with the first being found subsequently in sows This effect was probably operating more widely, as principal serovars appeared to be shared among the farms with common ownership, i.e. A and B (Derby, Kedougou), C and D (Give, Kedougou).

On Farm Z, an untypical serovar (Ohio) appeared to be dominant against a background of Derby and Typhimurium, serovars more typically found as endemic infections. $S$. Ohio can be found as a feedstuff contaminant, which may be the route by which it entered the herd and attained dominance at the time of sampling. As there was just one visit, it is unknown whether it was persistent, but it had achieved extensive spread on the farm, even into staff areas and a roadway. The absence of Salmonella in the farrowing accommodation was surprising, but this area was relatively isolated from effluent and faeces from elsewhere and had a good foot-dip system in place. It does not appear that farrowing and lactation are periods associated with increased maternal shedding of Salmonella (Nollet and others 2005a).

There was a significant correlation between the detection of some of the Salmonella serovars in pens and in the adjacent environment. This may be interpreted as a demonstration of the difficulty of containing Salmonella in one group of animals or within one area of a farm. Mobile farm equipment, such as weighing crates, piglet barrows and power washers, may have a significant vector role, given the frequency with which it was found to be contaminated by Salmonella in the present study. This would be worthy of attention even if selective sampling may have overstated the frequency of equipment contamination in the present study, and there may be a similar vector role for farm workers (Berends and others 1996).

All-in-all-out (AIAO) management appears to be ineffective for Salmonella control in pigs (Davies and others 1997). Reasons may include: difficulties in managing total depopulation of buildings, difficulties in the elimination of Salmonella by C\&D, and the tendency for transport between premises or buildings to stress the pigs and induce excretion of latent Salmonella infections (Berends and others 1996). AIAO management of post-weaning accommodation may be useful, but only if excellent C\&D is achieved.

The maintenance and dispersal of endemic Salmonella in breeding herds may be assisted by periodic introductions of gilts that may carry Salmonella and which are immunologically naïve to endemic strains (Davies and others 2000), plus cyclical movement of pigs through the breeding cycle. Furthermore, the more homogeneous genetic background of breeding animals and rapid turnover of breeding stock, particularly in nucleus herds, may in some cases increase susceptibility to infectious disease compared with crossbred commercial herds. Although biosecurity is important, it is the reduction of existing endemic infections that is likely to prove most useful in the control of Salmonella. Whilst the spread of infection is theoretically susceptible to stringent hygiene practices, particularly at weaning, there is little published work in this area specifically relating to breeding herds. Peracetic acid disinfection of farrowing and grower accommodation, plus the body surfaces of sows, resulted in no detectable Salmonella in farrowing units (Roesler and others 2005), but it did not prevent the infection of piglets and growers by endemic S. Typhimurium DT104. Neither did the 
addition of acidified feed and treatment of sows and piglets with enrofloxacin from a week before farrowing until weaning.

In the present study, C\&D of buildings, pens and equipment was generally found to be poor or inconsistent.Although our results do not compare contamination from the same areas before and after C\&D, the absolute failure of C\&D to eliminate Salmonella in most cases can be recognised. Furthermore, the relative success of $C \& D$ seen in farrowing areas is logical, given the priority normally afforded to C\&D in these areas. Results were good on one premises (D), where concentrated phenolic disinfectant was used rather than the more commonly used peroxygen products, and on another (E) after disinfection was repeated with formalin (data not shown). Effective disinfection under farm conditions has become more difficult since the withdrawal of taroil phenolic products. Whilst the absolute removal of Salmonella is commonly not achieved, evidence from poultry work (Carrique-Mas and others 2009) suggests that a substantial reduction in Salmonella challenge by good C\&D may contribute to a reduction in prevalence of infection, provided that other elements (especially rodents) are addressed.

There is strong circumstantial evidence of the involvement of rodents in the carriage and spread of Salmonella on the farms studied, inasmuch as rodent isolates correlated with prevailing pig Salmonella types and prevalences, at both unit and animal group levels. Other wildlife samples showed a similar correlation. To what extent these correlations simply reflect the prevailing environmental serovars rather than an active role for wildlife in Salmonella epidemiology on-farm cannot be determined on the present data, but it is logical to hypothesise that recontamination by wildlife of cleaned areas and of feed may frustrate otherwise effective decontamination. Salmonella may persist for at least several months within an infected rodent population (Henzler and Opitz 1992).

In summary, nucleus and multiplier herds may be at particular risk of Salmonella infection because of the detrimental effect of rapid stock turnover on herd immunity. They may also act as a source of Salmonella contamination for units that they supply, and the introduction of $S$. Derby (and possibly certain phage-types of $S$. Typhimurium) onto Farm Y by gilts illustrates the point. The breeding units examined appeared to be as susceptible to persistent Salmonella colonisation as units further down the production pyramid, especially on large farms with a high genetic turnover rate. Immature weaned stock appeared to be important in the epidemiology of at least one important serovar (Typhimurium), and attempts to detect this serovar on pig units should include sampling of these groups. As with production herds, wildlife, ineffective C\&D and importation of infected stock appear to be significant factors in the maintenance and re-introduction of Salmonella within these breeding herds. The unit with best control of Salmonella was small and had good separation of age groups, reasonable rodent control and practised effective C\&D.

\section{Acknowledgements}

This study was funded by Defra. The assistance of the owners and managers of the various pig units, and of VLA laboratory staff, is gratefully acknowledged. 


\section{References}

Anon (2005) Annual report of the Zoonoses Action Plan Salmonella programme July 2004 - June 2005. British Pig Executive - Meat and Livestock Commission. Milton Keynes, UK.

Anon (2006) Opinion of the Scientific Panel on Biological Hazards on "Risk assessment and mitigation options of Salmonella in pig production". EFSA Journal, 341, 1-131.

http://www.efsa.europa.eu/EFSA/efsa_locale-1178620753812_1178620776028.htm Accessed 16th Sept 2008

Anon (2007a) The Community summary report on trends and sources of zoonoses, zoonotic agents, antimicrobial resistance and foodborne outbreaks in the European Union in 2006. EFSA Journal, 130. http://www.efsa.europa.eu/en/science/monitoring_zoonoses/reports/zoonoses_report_2005.html Accessed 30th Sept 2008

Anon (2007b) Zoonoses report United Kingdom 2006. Department for Environment Food and Rural Affairs. London, DEFRA, pp. 11-24.

http://www.defra.gov.uk/animalh/diseases/zoonoses/reports.htm Accessed 30th Sept 2008

Anon (2008a) Report of the task force on zoonoses data collection on the analysis of the baseline survey on the prevalence of Salmonella in slaughter pigs, Part A: Salmonella prevalence estimates. EFSA Journal, 135, 1-111. http://www.efsa.europa.eu/EFSA/efsa_locale1178620753812_1178713190037.htm Accessed Sept 16th 2008

Anon (2008b) Salmonella in livestock production in GB 2007. Veterinary Laboratories Agency. http://www.defra.gov.uk/vla/reports/rep_salm_rep07.htm Accessed 30th Sept 2008

ARNOLD, M. E., COOK, A. \& DAVIES, R. (2005) A modelling approach to estimate the sensitivity of pooled faecal samples for isolation of Salmonella in pigs. Journal of The Royal Society Interface 2, 365-372

BAGGESEN, D. L., WEGENER, H. C., BAGER, F., STEGE, H. \& CHRISTENSEN, J. (1996) Herd prevalence of Salmonella enterica infections in Danish slaughter pigs determined by microbiological testing. Preventive Veterinary Medicine 26, 201-213

BERENDS, B. R., URLINGS, H. A. P., SNIJDERS, J. M. A. \& KNAPEN, F. V. (1996) Identification and quantification of risk factors in animal management and transport regarding Salmonella spp. in pigs. International Journal of Food Microbiology 30, 37-53

BOES, J., ALBAN, L., BAGGER, J., MOGELMOSE, V., BAGGESEN, D. L. \& OLSEN, J. E. (2005) Survival of Escherichia coli and Salmonella Typhimurium in slurry applied to clay soil on a Danish swine farm. Preventive Veterinary Medicine 69, 213-228

CARRIQUE-MAS, J. J., BRESLIN, M., SNOW, L., MCLAREN, I., SAYERS, A. R. \& DAVIES, R. H. (2009) Persistence and clearance of different Salmonella serovars in buildings housing laying hens. Epidemiology and Infection 137, 837-846

CHRISTENSEN, J., BAGGESEN, D. L., NIELSEN, B. \& STRYHN, H. (2002) Herd prevalence of Salmonella spp. in Danish pig herds after implementation of the Danish Salmonella Control Program with reference to a pre-implementation study. Veterinary Microbiology 88, 175-188 
COOK, A. C. J. (2004) Measuring the impact of Salmonella control in finishing pigs - lessons from a pilot study. The Pig Journal 53, 157-163

DAHL, J., WINGSTRAND, A., NIELSEN, B. \& BAGGESEN, D. L. (1997) Elimination of Salmonella typhimurium infection by the strategic movement of pigs. Veterinary Record 140, 679681

DAVIES, P. R., BOVEE, F. G., FUNK, J. A., MORROW, W. E. M., JONES, F. T. \& DEEN, J. (1998) Isolation of Salmonella serotypes from feces of pigs raised in a multiple-site production system. Journal of the American Veterinary Medical Association 212, 1925-1929

DAVIES, P. R., FUNK, J. A. \& MORROW, W. E. M. (2000) Fecal shedding of Salmonella by gilts before and after introduction to a swine breeding farm. Swine Health and Production 8, 25-29

DAVIES, P. R., MORROW, W. E. M., JONES, F. T., DEEN, J., FEDORKA-CRAY, P. J. \& HARRIS, I. T. (1997) Prevalence of Salmonella in finishing swine raised in different production systems in North Carolina, USA. Epidemiology and Infection 119, 237-244

DAVIES, R. H., DALZIEL, R., GIBBENS, J. C., WILESMITH, J. W., RYAN, J. M. B., EVANS, S. J., BYRNE, C., PAIBA, G. A., PASCOE, S. J. S. \& TEALE, C. J. (2004) National survey for Salmonella in pigs, cattle and sheep at slaughter in Great Britain (1999-2000). Journal of Applied Microbiology 96, 750-760

DAVIES, R. H. \& WRAY, C. (1996) Persistence of Salmonella enteritidis in poultry units and poultry food. British Poultry Science 37, 589-596

DAVIES, R. H. \& WRAY, C. (1997) Distribution of Salmonella on 23 pig farms in the UK. Proceedings of 2nd International Symposium on epidemiology and control of Salmonella in pork. Copenhagen, Aug 20-22, 1997

FUNK, J. A., DAVIES, P. R. \& NICHOLS, M. A. (2001) Longitudinal study of Salmonella enterica in growing pigs reared in multiple-site swine production systems. Veterinary Microbiology 83, 45-60

GOLDSTEIN, H. (2003) Multilevel statistical models (Kendall's library of statistics). London, Hodder Arnold

GRAFANAKIS, E., LEONTIDES, L. \& GENIGEORGIS, C. (2001) Seroprevalence and antibiotic sensitivity of serotypes of Salmonella enterica in Greek pig herds. Veterinary Record 148, 407-411

HENZLER, D. J. \& OPITZ, H. M. (1992) The role of mice in the epizootiology of Salmonella enteritidis infection on chicken layer farms. Avian Diseases 36, 625-631

KRANKER, S., ALBAN, L., BOES, J. \& DAHL, J. (2003) Longitudinal study of Salmonella enterica serotype Typhimurium infection in three Danish farrow-to-finish swine herds. Journal of Clinical Microbiology 41, 2282-2288

LARSEN, S. T., MCKEAN, J. D., HURD, H. S., ROSTAGNO, M. H., GRIFFITH, R. W. \& WESLEY, I. V. (2003) Impact of commercial preharvest transportation and holding on the prevalence of Salmonella enterica in cull sows. Journal of Food Protection 66, 1134-1138

LETELLIER, A., MESSIER, S., PARE, J., MENARD, J. \& QUESSY, S. (1999) Distribution of Salmonella in swine herds in Quebec. Veterinary Microbiology 67, 299-306 
NIELSEN, B., BAGGESEN, D., BAGER, F., HAUGEGAARD, J. \& LIND, P. (1995) The serological response to Salmonella serovars typhimurium and infantis in experimentally infected pigs. The time course followed with an indirect anti-LPS ELISA and bacteriological examinations. Veterinary Microbiology 47, 205-218

NIETFELD, J. C., FEDER, I., KRAMER, T. T., SCHONEWEIS, D. \& CHENGAPPA, M. M. (1998) Preventing Salmonella infection in pigs with offsite weaning. Swine Health and Production 6, 27-32

NOLLET, N., HOUF, K., DEWULF, J., DE KRUIF, A., DE ZUTTER, L. \& MAES, D. (2005a) Salmonella in sows: a longitudinal study in farrow-to-finish pig herds. Veterinary Research 36, 645656

NOLLET, N., HOUF, K., DEWULF, J., DUCHATEAU, L., DE ZUTTER, L., DE KRUIF, A. \& MAES, D. (2005b) Distribution of Salmonella strains in farrow-to-finish pig herds: A longitudinal study. Journal of Food Protection 68, 2012-2021

NOLLET, N., MAES, D., DE ZUTTER, L., DUCHATEAU, L., HOUF, K., HUYSMANS, K., IMBERECHTS, H., GEERS, R., DE KRUIF, A. \& VAN HOOF, J. (2004) Risk factors for the herdlevel bacteriologic prevalence of Salmonella in Belgian slaughter pigs. Preventive Veterinary Medicine 65, 63-75

REED, W. M., OLANDER, H. J. \& THACKER, H. L. (1985) Studies on the pathogenesis of Salmonella heidelberg infection in weanling pigs. American Journal of Veterinary Research 46, 2300-2310

REED, W. M., OLANDER, H. J. \& THACKER, H. L. (1986) Studies on the pathogenesis of Salmonella typhimurium and Salmonella choleraesuis var kunzendorf infection in weanling pigs. American Journal of Veterinary Research 47, 75-83

ROESLER, U., HELLER, P., WALDMANN, K. H., TRUYEN, U. \& HENSEL, A. (2006) Immunization of sows in an integrated pig-breeding herd using a homologous inactivated Salmonella vaccine decreases the prevalence of Salmonella Typhimurium infection in the offspring. Journal of Veterinary Medicine Series B 53, 224-228

ROESLER, U., VON ALTROCK, A., HELLER, P., BREMERICH, S., ARNOLD, T., LEHMANN, J., WALDMANN, K. H., TRUYEN, U. \& HENSEL, A. (2005) Effects of fluorequinolone treatment acidified feed, and improved hygiene measures on the occurrence of Salmonella Typhimurium DT104 in an integrated pig breeding herd. Journal of Veterinary Medicine Series B 52, 69-74

THRUSFIELD, M. (1995) Veterinary epidemiology. 2nd edn. Oxford, UK, Blackwell Science Ltd. pp 224-225

VAN DER WOLF, P. J., ELBERS, A. R. W., VAN DER HEIJDEN, H. M. J. F., VAN SCHIE, F. W., HUNNEMAN, W. A. \& TIELEN, M. J. M. (2001) Salmonella seroprevalence at the population and herd level in pigs in The Netherlands. Veterinary Microbiology 80, 171-184

WHEELER, J. G., SETHI, D., COWDEN, J. M., WALL, P. G., RODRIGUES, L. C., TOMPKINS, D. S., HUDSON, M. J. \& RODERICK, P. J. (1999) Study of infectious intestinal disease in England: rates in the community, presenting to general practice, and reported to national surveillance. British Medical Journal 318, 1046-1050 
WOOD, R. L., POSPISCHIL, A. \& ROSE, R. (1989) Distribution of persistent Salmonella typhimurium infection in internal organs of swine. American Journal of Veterinary Research 50, 1015-1021

YOU, Y. W., RANKIN, S. C., ACETO, H. W., BENSON, C. E., TOTH, J. D. \& DOU, Z. X. (2006) Survival of Salmonella enterica serovar Newport in manure and manure-amended soils. Applied and Environmental Microbiology 72, 5777-5783 
Table 1: Summary of Salmonella isolations from the various categories of stock on each farm.

\begin{tabular}{|c|c|c|c|c|c|c|c|c|c|c|}
\hline & \multicolumn{8}{|l|}{ Farm } & \multicolumn{2}{|c|}{ Farm type } \\
\hline & $\mathrm{A}$ & $\mathrm{B}$ & $\mathrm{C}$ & $\mathrm{D}$ & $\mathrm{E}$ & $\mathrm{X}$ & $\mathrm{Y}$ & $\mathrm{Z}$ & Nucleus & Multiplier \\
\hline \multicolumn{11}{|l|}{ Boars/Service areas } \\
\hline All serovars & & 27 & 5 & 0 & 17 & 42 & 8 & 95 & 49 & 145 \\
\hline non-Typhimurium & & 24 & 4 & 0 & 13 & 19 & 5 & & 41 & 24 \\
\hline Typhimurium & & 3 & 1 & 0 & 4 & 23 & 3 & $++^{a}$ & 8 & 26 \\
\hline Total samples taken & 0 & 41 & 23 & 1 & 40 & 164 & 87 & 107 & 105 & 358 \\
\hline \multicolumn{11}{|l|}{ Dry sows } \\
\hline All serovars & 61 & 56 & 17 & 15 & 22 & 111 & 14 & 36 & 171 & 161 \\
\hline non-Typhimurium & 61 & 52 & 17 & 15 & 22 & 69 & 12 & & 167 & 81 \\
\hline Typhimurium & 0 & 4 & 0 & 0 & 0 & 42 & 2 & $-{ }^{b}$ & 4 & 44 \\
\hline Total samples taken & 162 & 63 & 24 & 62 & 43 & 244 & 171 & 40 & 354 & 455 \\
\hline \multicolumn{11}{|l|}{ Farrowing areas } \\
\hline All serovars & 26 & 55 & 80 & 1 & 21 & 115 & 35 & 0 & 183 & 150 \\
\hline non-Typhimurium & 26 & 55 & 76 & 1 & 16 & 98 & 20 & & 174 & 118 \\
\hline Typhimurium & 0 & 0 & 4 & 0 & 5 & 17 & 15 & $-{ }^{b}$ & 9 & 32 \\
\hline Total samples taken & 105 & 147 & 123 & 42 & 51 & 541 & 221 & 151 & 468 & 913 \\
\hline \multicolumn{11}{|l|}{ Young boars \& gilts } \\
\hline All serovars & 193 & 73 & 33 & & 8 & 129 & 15 & & 307 & 144 \\
\hline non-Typhimurium & 162 & 61 & 29 & & 8 & 42 & 5 & & 260 & 47 \\
\hline Typhimurium & 31 & 12 & 4 & & 0 & 87 & 10 & & 47 & 97 \\
\hline Total samples taken & 327 & 191 & 33 & 0 & 10 & 300 & 61 & 0 & 561 & 361 \\
\hline \multicolumn{11}{|l|}{ Finishers } \\
\hline All serovars & & & 146 & & 37 & & & & 183 & 0 \\
\hline non-Typhimurium & & & 97 & & 18 & & & & 115 & 0 \\
\hline Typhimurium & & & 49 & & 19 & & & & 68 & 0 \\
\hline Total samples taken & 0 & 0 & 229 & 0 & 55 & 0 & 0 & 0 & 284 & 0 \\
\hline \multicolumn{11}{|l|}{ Weaners \& growers } \\
\hline All serovars & 44 & 73 & 102 & 2 & 30 & 307 & 60 & 76 & 251 & 443 \\
\hline non-Typhimurium & 43 & 37 & 57 & 2 & 13 & 119 & 15 & & 152 & 134 \\
\hline Typhimurium & 1 & 36 & 45 & 0 & 17 & 188 & 45 & $+{ }^{\mathrm{a}}$ & 99 & 233 \\
\hline Total samples taken & 109 & 192 & 124 & 27 & 48 & 755 & 233 & 100 & 500 & 1088 \\
\hline \multicolumn{11}{|l|}{ All stock categories } \\
\hline All serovars & 324 & 284 & 383 & 18 & 135 & 704 & 132 & 207 & 1144 & 1043 \\
\hline non-Typhimurium & 292 & 229 & 280 & 18 & 90 & 347 & 57 & & 909 & 404 \\
\hline Typhimurium & 32 & 55 & 103 & 0 & 45 & 357 & 75 & & 235 & 432 \\
\hline Total samples taken & 703 & 634 & 556 & 132 & 247 & 2004 & 773 & 398 & 2272 & 3175 \\
\hline
\end{tabular}

${ }^{a} S$. Typhimurium detected in some samples, but heavy masking by other salmonellae prevented confident determination of the number of affected samples. b No $S$. Typhimurium seen, but possible masking by other salmonellae did not allow a zero value to be given confidently. 
Table 2: Adjusted odds ratios from a hierarchical logistic regression model examining the isolation of Salmonella spp, $S$. Typhimurium and non-Typhimurium serovars from different categories of stock.

\begin{tabular}{|c|c|c|c|c|c|c|c|c|c|}
\hline \multirow[b]{2}{*}{ Type of sample } & \multicolumn{3}{|c|}{ non-Typhimurium serovars } & \multicolumn{3}{|c|}{ S. Typhimurium } & \multicolumn{3}{|c|}{ All serovars } \\
\hline & $\begin{array}{l}\text { Positive/ } \\
\text { total } \\
\text { samples }\end{array}$ & OR & $95 \% \mathrm{CI}$ & $\begin{array}{l}\text { Positive/ } \\
\text { total } \\
\text { samples }\end{array}$ & OR & $95 \% \mathrm{CI}$ & $\begin{array}{l}\text { Positive/ } \\
\text { total } \\
\text { samples }\end{array}$ & OR & $95 \% \mathrm{CI}$ \\
\hline Farrowing areas & $292 / 1230$ & Ref. & - & $41 / 1230$ & Ref. & - & $333 / 1230$ & Ref. & - \\
\hline Boars/service areas & $65 / 356$ & 1.10 & $0.49-2.43$ & $34 / 356$ & 2.59 & $1.71-3.90$ & $99 / 356$ & 1.25 & $0.61-2.57$ \\
\hline Dry sows & $248 / 769$ & 2.08 & $1.03-4.23$ & $48 / 769$ & 2.46 & $1.80-3.37$ & $296 / 769$ & 2.23 & $1.16-4.30$ \\
\hline Young boars \& gilts & $307 / 922$ & 1.43 & $0.68-2.99$ & $144 / 922$ & 7.39 & $1.15-47.56$ & $451 / 922$ & 2.32 & $1.19-4.54$ \\
\hline Weaners \& growers & $286 / 1488$ & 0.88 & $0.41-1.87$ & $332 / 1488$ & 6.82 & $4.79-9.71$ & $618 / 1488$ & 1.93 & $1.42-2.61$ \\
\hline
\end{tabular}

$\mathrm{OR}=$ odds ratio; $\mathrm{CI}=$ confidence interval

Table 3: Risk ratios and significance tests for associations between individual Salmonella serovars in groups of pens and in their immediate environs.

\begin{tabular}{|c|c|c|c|c|c|c|c|}
\hline \multirow[b]{2}{*}{ Serovar } & \multicolumn{2}{|l|}{$\begin{array}{l}\text { Positive } \\
\text { adjacent } \\
\text { environment }\end{array}$} & \multicolumn{2}{|l|}{$\begin{array}{l}\text { Negative } \\
\text { adjacent } \\
\text { environment* }\end{array}$} & \multirow[b]{2}{*}{$\mathbf{R R}$} & \multirow[b]{2}{*}{$95 \% \mathrm{CI}$} & \multirow{2}{*}{$\begin{array}{l}\text { Fisher's } \\
\text { exact test } \\
\text { p-value }\end{array}$} \\
\hline & +ve pens/total & $\mathrm{P}$ & +ve pens/total & $\mathrm{P}$ & & & \\
\hline Typhimurium & $7 / 8$ & 0.88 & $7 / 26$ & 0.27 & 3.25 & $1.64-6.45$ & 0.004 \\
\hline Give & $4 / 4$ & 1.0 & $2 / 3$ & 0.66 & 1.50 & $0.67-3.34$ & 0.428 \\
\hline Panama & $2 / 2$ & 1.0 & $1 / 14$ & 0.07 & 14.00 & $2.12-92.55$ & 0.002 \\
\hline Derby & $2 / 3$ & 0.67 & $3 / 27$ & 0.11 & 6.0 & $1.58-22.77$ & 0.064 \\
\hline Manhattan & $1 / 2$ & 0.50 & $5 / 9$ & 0.55 & 0.90 & $0.20-4.05$ & 1.0 \\
\hline
\end{tabular}

$\mathrm{P}=$ Probability; $\mathrm{RR}=$ Risk Ratio; $\mathrm{CI}=$ Confidence intervals; $\mathrm{NC}=$ Not calculated. ${ }^{*}$ Totals in this column are derived only from visits where the respective serovar was isolated 
Table 4: Comparison of samples, taken at the same visits, from uncleaned areas and from areas after cleaning and disinfection (C\&D).

\begin{tabular}{|c|c|c|c|c|c|c|c|c|c|}
\hline \multirow[b]{2}{*}{ Area } & \multirow{2}{*}{$\begin{array}{l}\text { Farm/ } \\
\text { visit }\end{array}$} & \multicolumn{4}{|c|}{ Samples from uncleaned areas } & \multicolumn{4}{|c|}{ Samples after C\&D } \\
\hline & & Salm. + & Total & $\% *$ & Serovars $^{\dagger}$ & Salm. + & Total & $\% *$ & Serovars $^{\dagger}$ \\
\hline \multirow{11}{*}{$\begin{array}{l}\text { Farrowing } \\
\text { crates }\end{array}$} & $\mathrm{A} / 1$ & 13 & 29 & 45 & $\mathrm{~K}, \mathrm{~N}$ & 7 & 10 & 70 & $\mathrm{~K}$ \\
\hline & $\mathrm{B} / 2$ & 4 & 6 & 67 & $\mathrm{~K}$ & 4 & 29 & 14 & $\mathrm{~K}$ \\
\hline & $\mathrm{D} / 1$ & 1 & 42 & 2 & G & 0 & 18 & 0 & \\
\hline & $E / 1$ & 10 & 18 & 56 & $\mathrm{~B}, \mathrm{Mb}, \mathrm{St}$ & 1 & 4 & 25 & St \\
\hline & $\mathrm{X} / 1$ & 22 & 73 & 30 & $\mathrm{D}, \mathrm{Ma}, \mathrm{T}$ & 2 & 16 & 13 & $\mathrm{~T}$ \\
\hline & $\mathrm{X} / 3$ & 5 & 72 & 7 & $\mathrm{Ma}, \mathrm{T}$ & 0 & 18 & 0 & \\
\hline & $\mathrm{X} / 7$ & 9 & 72 & 13 & $\mathrm{D}, \mathrm{Ma}$ & 0 & 2 & 0 & \\
\hline & $\mathrm{Y} / 1$ & 11 & 47 & 23 & $\mathrm{P}$ & 5 & 13 & 38 & $\mathrm{P}$ \\
\hline & $\mathrm{Y} / 3$ & 9 & 40 & 23 & $\mathrm{P}$ & 0 & 6 & 0 & \\
\hline & $\mathrm{Y} / 4$ & 0 & 32 & 0 & & 0 & 15 & 0 & \\
\hline & $\mathrm{Y} / 5$ & 14 & 45 & 31 & $\mathrm{~T}$ & 0 & 6 & 0 & \\
\hline $\begin{array}{l}\text { Farrowing } \\
\text { environment }\end{array}$ & Y/5 & 3 & 13 & 23 & $\mathrm{~T}$ & 2 & 2 & 100 & $\mathrm{~T}$ \\
\hline \multicolumn{2}{|c|}{$\begin{array}{l}\text { Subtotals farrowing } \\
\text { house }\end{array}$} & 101 & 489 & 21 & & 21 & 139 & 15 & \\
\hline \multirow[t]{2}{*}{ Weaner pens } & $\mathrm{E} / 1$ & 1 & 9 & 11 & $\mathrm{St}$ & 3 & 7 & 43 & $\mathrm{St}$ \\
\hline & $\mathrm{E} / 2$ & 7 & 13 & 54 & $\mathrm{~T}$ & 5 & 9 & 56 & $\mathrm{~T}$ \\
\hline \multirow[t]{2}{*}{ Flat decks } & $\mathrm{X} / 7$ & 0 & 12 & 0 & & 0 & 22 & 0 & \\
\hline & $\mathrm{X} / 8$ & 0 & 34 & 0 & & 0 & 2 & 0 & \\
\hline \multirow[t]{2}{*}{ Fatteners } & $\mathrm{E} / 1$ & 1 & 1 & 100 & St & 0 & 5 & 0 & \\
\hline & $\mathrm{E} / 2$ & 19 & 32 & 59 & $\mathrm{~T}$ & 10 & 15 & 67 & $\mathrm{St}, \mathrm{T}$ \\
\hline \multirow[t]{2}{*}{ Lairage } & $\mathrm{X} / 1$ & 2 & 3 & 67 & $\mathrm{~T}$ & 7 & 12 & 58 & $\mathrm{~T}$ \\
\hline & $X / 3$ & 5 & 5 & 100 & $\mathrm{~T}$ & 6 & 9 & 67 & $\mathrm{~T}$ \\
\hline \multicolumn{2}{|c|}{$\begin{array}{l}\text { Subtotals } \\
\text { non-farrowing }\end{array}$} & 35 & 109 & 32 & & 31 & 81 & 38 & \\
\hline \multicolumn{2}{|l|}{ Totals } & 136 & 598 & 23 & & 52 & 220 & 24 & \\
\hline
\end{tabular}

*Proportion of Salmonella-positive samples, expressed as percent. ${ }^{\dagger}$ B: Bredeney. D: Derby. G: Give. K: Kedougou. Ma: Manhattan. Mb: Mbandaka. N: Newport. P: Panama. St: Stanley. T: Typhimurium. 
Table 5: Comparison of wildlife samples with all other samples on farms. Farms and visits without wildlife samples are not included.

\begin{tabular}{|c|c|c|c|c|c|c|c|c|c|c|}
\hline \multirow{2}{*}{$\begin{array}{l}\text { Farm / } \\
\text { visit }\end{array}$} & \multicolumn{4}{|c|}{ Non-vector samples } & \multicolumn{2}{|c|}{ Rodent faeces/carcasses } & \multicolumn{2}{|c|}{ Wild bird faeces } & \multicolumn{2}{|c|}{ Other potential vectors } \\
\hline & Positive & Total & $\% *$ & Serovars ${ }^{\dagger}$ & $\% *(+/$ tot. $)$ & Serovars $^{\dagger}$ & $\% *(+/$ tot. $)$ & Serovars $^{\dagger}$ & $\% *(+/ \text { tot. })^{\ddagger}$ & (source) Serovars ${ }^{\dagger}$ \\
\hline $\mathrm{A} / 1$ & 89 & 145 & 61 & $\mathrm{D}, \mathrm{K}, \mathrm{T} \underline{104}, \mathrm{~T} \underline{20}$ & $75 \quad(6 / 8)$ & $\mathrm{D}, \mathrm{K}, \mathrm{T} \underline{104}$ & $50 \quad(3 / 6)$ & $\mathrm{D}, \mathrm{T} \underline{104}$ & $100(1 / 1)$ & (fox) $\mathrm{T} \underline{104}$ \\
\hline $\mathrm{A} / 2$ & 144 & 300 & 48 & $\mathrm{D}, \mathrm{K}, \mathrm{T} \underline{104}, \mathrm{~T} \underline{104 B},(\mathrm{Se})$ & & & $0 \quad(0 / 1)$ & & & \\
\hline $\mathrm{A} / 3$ & 122 & 305 & 40 & $\mathrm{D}, \mathrm{K},(\mathrm{A})$ & $0 \quad(0 / 3)$ & & $0 \quad(0 / 2)$ & & & \\
\hline $\mathrm{B} / 1$ & 60 & 167 & 36 & $\mathrm{~K}, \mathrm{~N}, \mathrm{~T} 104,(\mathrm{Me}, \mathrm{D})$ & $17(1 / 6)$ & $\mathrm{K}$ & & & & \\
\hline $\mathrm{B} / 2$ & 101 & 282 & 36 & $\mathrm{D}, \mathrm{K}, \mathrm{N}, \mathrm{T} \underline{104},(\mathrm{Aj}, \mathrm{T} \underline{120})$ & $11(1 / 9)$ & $\mathrm{N}$ & $29(2 / 7)$ & $\mathrm{K}$ & $0(0 / 1)$ & (fox) \\
\hline $\mathrm{B} / 3$ & 150 & 261 & 57 & $\mathrm{D}, \mathrm{N}, \mathrm{K}, \mathrm{T} \underline{104}$ & $60 \quad(3 / 5)$ & $\mathrm{D}, \mathrm{T}$ & $67 \quad(2 / 3)$ & $\mathrm{D}$ & $0(0 / 1)$ & (fox) \\
\hline $\mathrm{C} / 1$ & 225 & 321 & 70 & $\mathrm{G}, \mathrm{K}, \mathrm{T} \underline{104}, \mathrm{~T} 193$ & $36(4 / 11)$ & $\mathrm{G}, \mathrm{T} 193$ & $0 \quad(0 / 2)$ & & & \\
\hline $\mathrm{C} / 2$ & 180 & 284 & 63 & $\mathrm{~A}, \mathrm{G}, \mathrm{R}, \mathrm{T} \underline{104}$ & $20(1 / 5)$ & $\mathrm{G}$ & $100(3 / 3)$ & $\mathrm{G}$ & & \\
\hline $\mathrm{D} / 1$ & 29 & 201 & 14 & $\mathrm{G}, \mathrm{K}$ & $17(1 / 6)$ & $\mathrm{G}$ & $0 \quad(0 / 4)$ & & $0(0 / 1)$ & (flies) \\
\hline $\mathrm{E} / 1$ & 109 & 199 & 55 & $\mathrm{~B}, \mathrm{Mb}, \mathrm{St}, \mathrm{T}$ & $57(8 / 14)$ & B, St, T & $50 \quad(4 / 8)$ & & $100(2 / 2)$ & (flies) St; (fox) $\mathrm{T}$ \\
\hline $\mathrm{E} / 2$ & 120 & 198 & 61 & $\mathrm{~B}, \mathrm{Mb}, \mathrm{St}, \mathrm{T},(\mathrm{K})$ & $100(1 / 1)$ & St & $45(5 / 11)$ & B & & \\
\hline $\mathrm{X} / 1$ & 244 & 430 & 57 & $\mathrm{~B}, \mathrm{D}, \mathrm{Ma}, \mathrm{N}, \mathrm{T}$ & $50 \quad(4 / 8)$ & $\mathrm{Ma}, \mathrm{T}$ & $100 \quad(2 / 2)$ & $\mathrm{T}$ & $100(1 / 1)$ & $\mathrm{T}$ \\
\hline $\mathrm{X} / 3$ & 150 & 616 & 24 & $\mathrm{Ma}, \mathrm{T}$ & $56(5 / 9)$ & $\mathrm{T}$ & $33(1 / 3)$ & $\mathrm{T}$ & $40(2 / 5)$ & (flies) $\mathrm{Ma}, \mathrm{T}$; (fox) \\
\hline $\mathrm{X} / 4$ & 173 & 383 & 45 & Ma, T & $17(2 / 12)$ & Ma, T & $0 \quad(0 / 5)$ & & $100(2 / 2)$ & (flies) Ma \\
\hline $\mathrm{X} / 5$ & 59 & 263 & 22 & $\mathrm{D}, \mathrm{Ma}, \mathrm{Mu}, \mathrm{D}, \mathrm{T},(\mathrm{T} \underline{U 302})$ & & & $0 \quad(0 / 2)$ & & & \\
\hline $\mathrm{X} / 7$ & 48 & 297 & 16 & $\mathrm{D}, \mathrm{Ma}, \mathrm{T}$ & & & $25(1 / 4)$ & $\mathrm{T}$ & & \\
\hline $\mathrm{X} / 8$ & 73 & 292 & 25 & $\mathrm{D}, \mathrm{H}, \mathrm{Ma},(\mathrm{T}, \mathrm{Mo})$ & & & $0 \quad(0 / 3)$ & & & \\
\hline $\mathrm{Y} / 1$ & 38 & 266 & 14 & $\mathrm{P},(\mathrm{T} \underline{208})$ & $0 \quad(0 / 1)$ & & $33(4 / 12)$ & $\mathrm{P}, \mathrm{T} 2 \underline{208}$ & $0(0 / 1)$ & (cat) \\
\hline $\mathrm{Y} / 2$ & 18 & 226 & 8 & $\mathrm{~T} 104, \mathrm{~T} 208$ & $0 \quad(0 / 1)$ & & $14(2 / 14)$ & $\mathrm{T}$ & $0(0 / 3)$ & (cat, fox) \\
\hline $\mathrm{Y} / 3$ & 49 & 131 & 37 & $\mathrm{D}, \mathrm{P}$ & $80 \quad(4 / 5)$ & $\mathrm{P}$ & $44 \quad(4 / 9)$ & $\mathrm{P}$ & $0(0 / 5)$ & (dog, fox, peacock) \\
\hline $\mathrm{Y} / 4$ & 4 & 204 & 2 & $\mathrm{D}, \mathrm{P}, \mathrm{T} \underline{104 B}$ & & & $0 \quad(0 / 4)$ & & $0(0 / 1)$ & $(\operatorname{dog})$ \\
\hline $\mathrm{Y} / 5$ & 109 & 243 & 45 & $\mathrm{~T},(\mathrm{P})$ & & & $33(2 / 6)$ & $\mathrm{T}$ & & \\
\hline $\mathrm{Z}$ & 260 & 474 & 55 & $\mathrm{D}, \mathrm{O}, \mathrm{T} \underline{U 288}$ & $33(4 / 12)$ & $\mathrm{D}, \mathrm{O}$ & $17 \quad(1 / 6)$ & & $0(0 / 3)$ & (rabbit, cat, dog) \\
\hline Totals & 2554 & 6488 & 39 & & $39(45 / 116)$ & & $31(36 / 117)$ & & $30(8 / 27)$ & \\
\hline
\end{tabular}

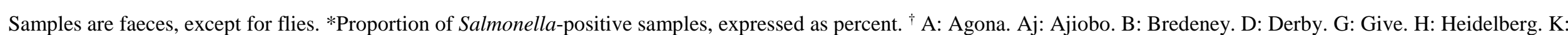
Kedougou. Ma: Manhattan. Mb: Mbandaka. Me: Meleagridis. Mo: Montevideo. Mu: Muenchen. N: Newport. O: Ohio. P: Panama. R: Rissen. Se: Senftenberg. St: Stanley.

T: Typhimurium, +/-phage-type. Serovars in brackets were uncommon isolates on the respective visits. ${ }^{\ddagger}$ Number of positives/total number of samples. 

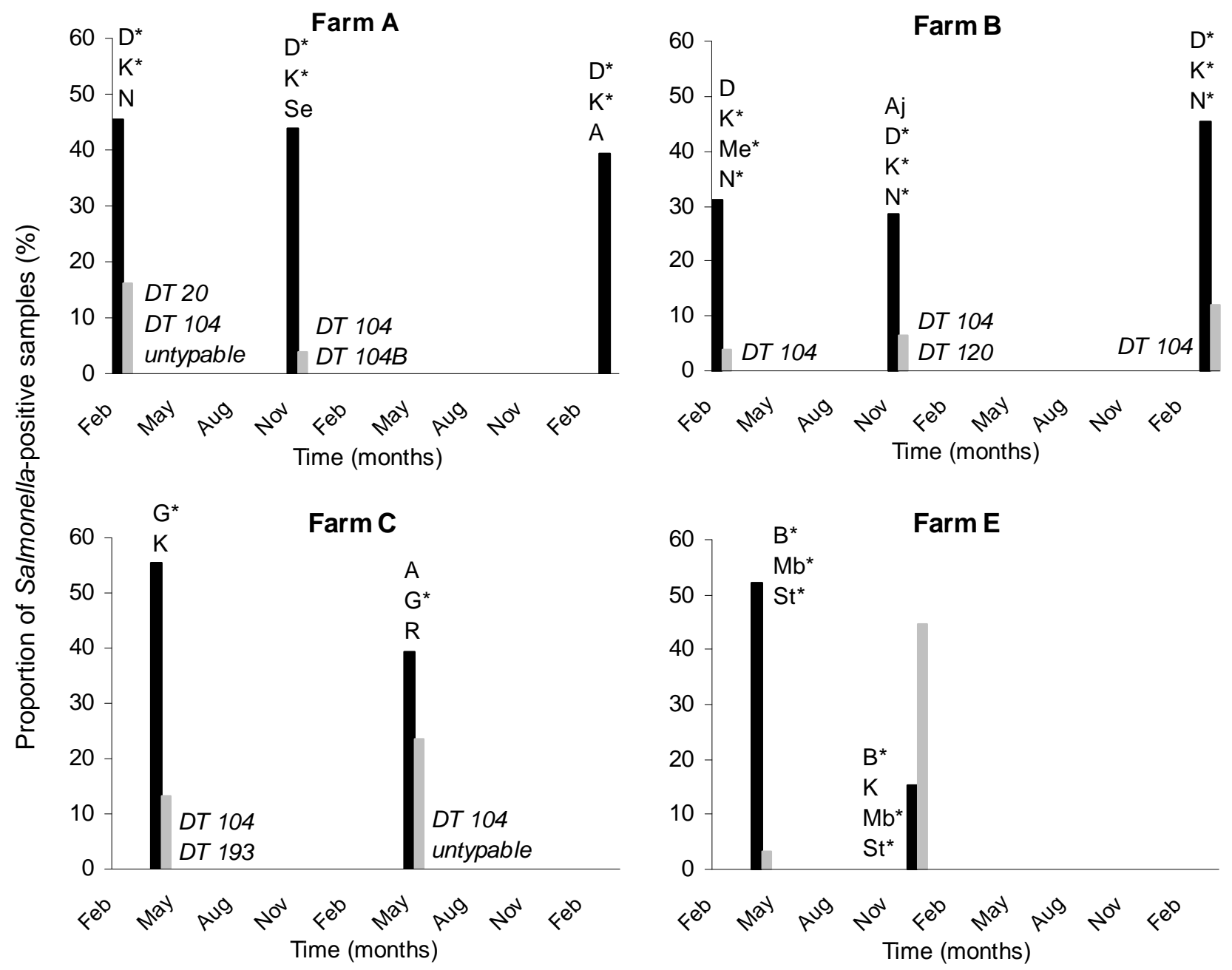

Figure 1: Overall prevalence values of Salmonella Typhimurium (grey bars) and non-

Typhimurium serovars (black bars) over time, for farms visited more than once (A, B, C, E). Isolated serovars, or phage-types for $S$. Typhimurium, are listed for each sampling occasion.

A: Agona. Aj: Ajiobo. B: Bredeney. D: Derby. G: Give. K: Kedougou. Mb: Mbandaka. Me: Meleagridis. N: Newport. R: Rissen. Se: Senftenberg. St: Stanley. DT: Typhimurium + phage-type. Untypable: S. Typhimurium not phagetypable. * Predominant serovars. 


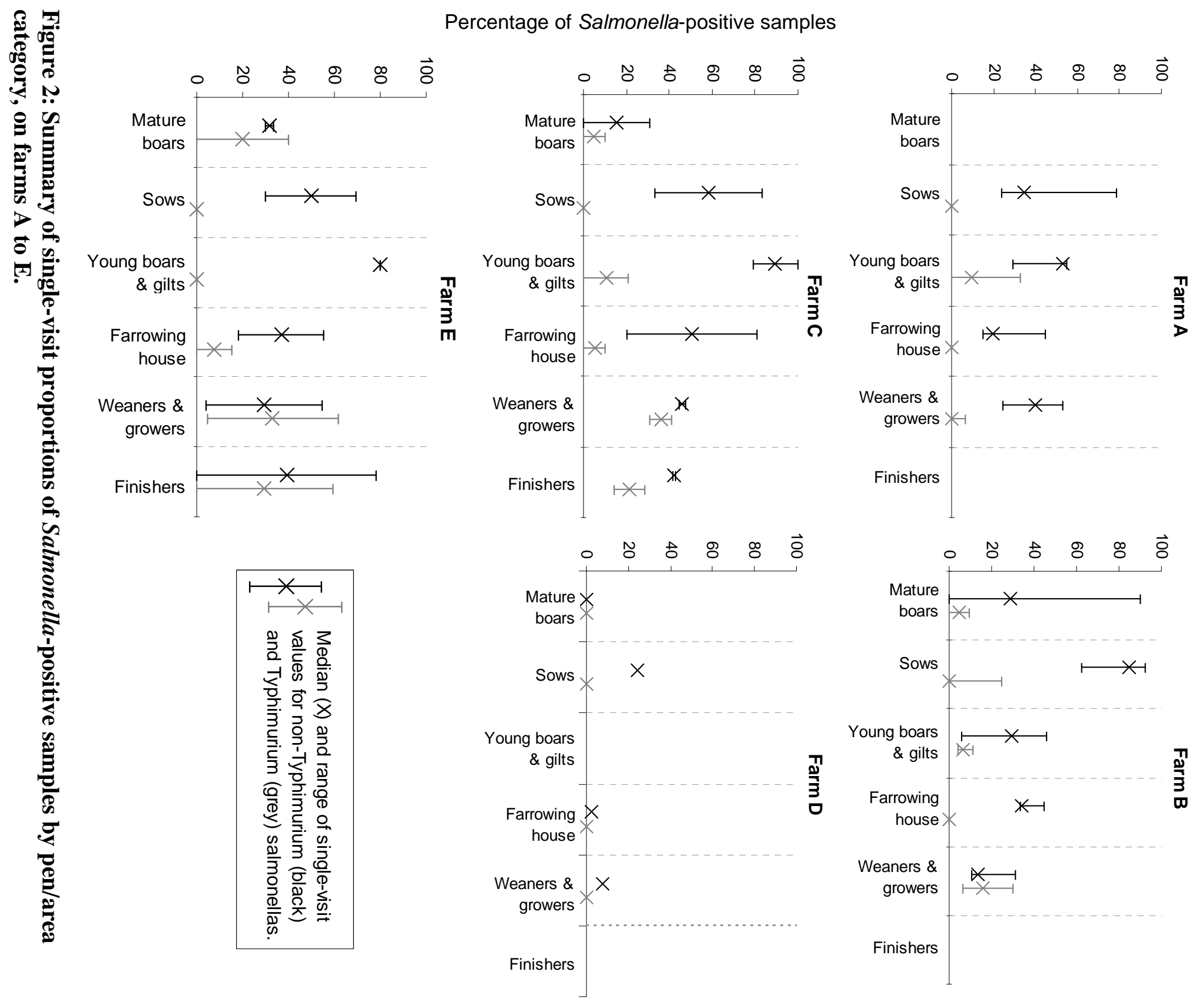




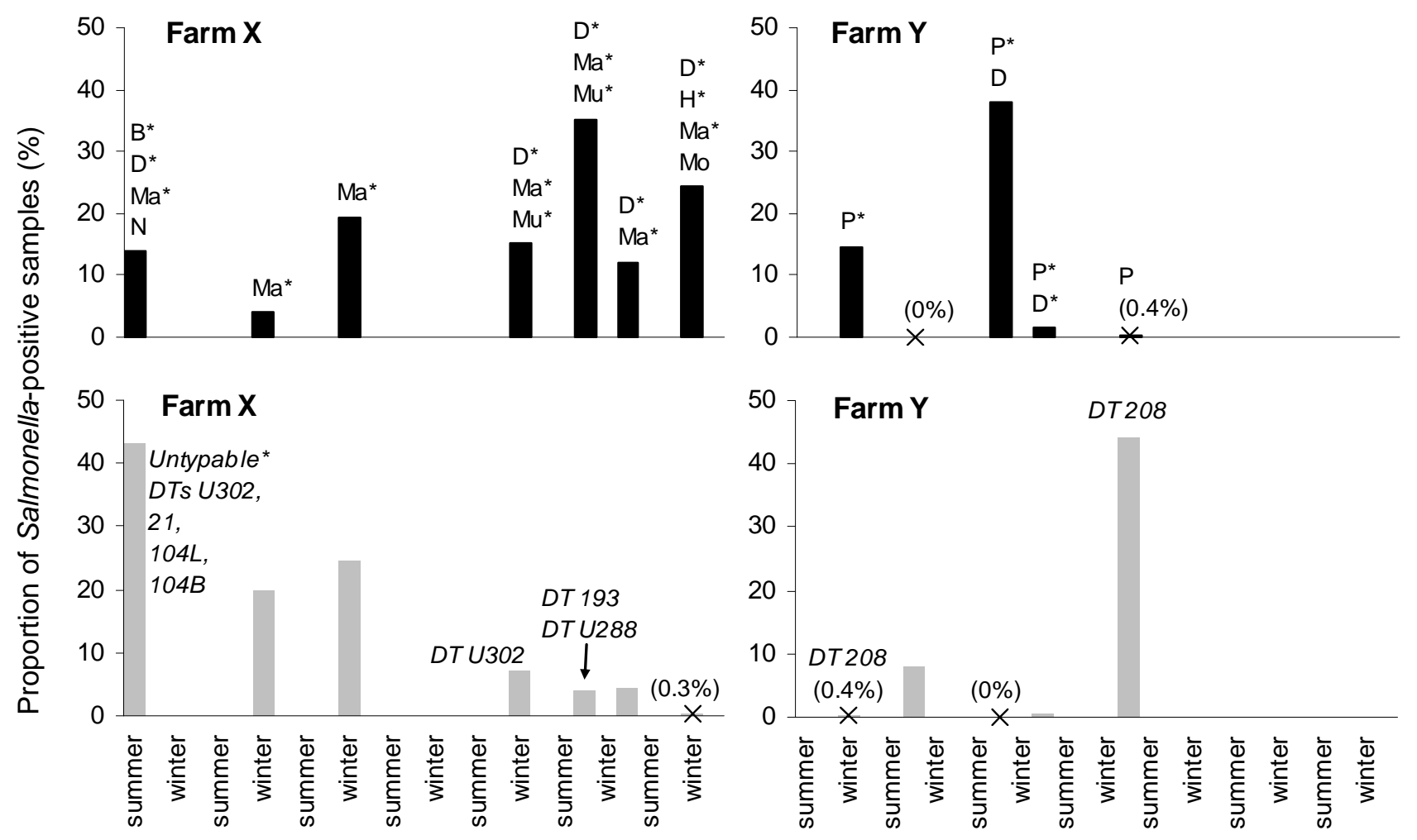

Figure 3: Prevalence values of Salmonella Typhimurium (grey bars) and non-Typhimurium (black bars) over time. Results of serotyping (upper charts) and phage-typing (lower charts) are listed against corresponding sampling occasions. Time scales on lower charts apply to all charts.

B: Bredeney. D: Derby. H: Heidelberg. Ma: Manhattan. Mo: Montevideo. Mu: Muenchen. N: Newport. P: Panama. DT: Typhimurium phage-type. * Predominant serovars.

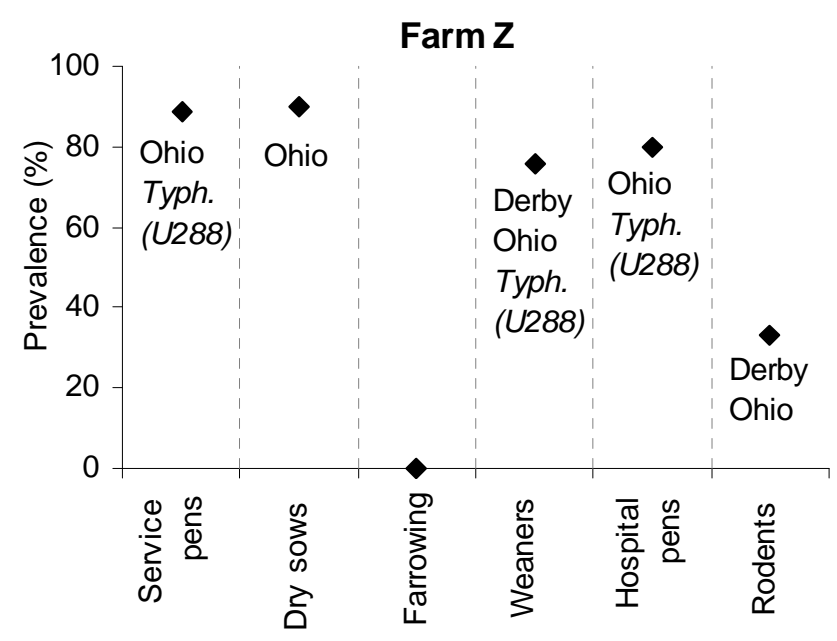

Figure 4: Proportions of Salmonella-positive samples from pens and rodents on Farm Z. Serovars are listed.

Typh. (U288): Salmonella Typhimurium definitive phage-type U288 